\title{
LOCAL CLASSIFICATION OF DIFFERENTIATED THYROID CANCER. DOES IT ALLOWS TO DISCRIMINATE THE RESPONSE TO TREATMENT?
}

\author{
F. Gajardo, C. Pereira, V. Inostroza, C. Campos, P. Invernizzi , F. Vásquez, P. Hernández, A. Ladrón de Guevara, M. \\ Domínguez, E. Díaz, N. Crisosto. \\ Unit of Endocrinology, Hospital San Juan de Dios, Santiago, Chile.
}

INTRODUCTION: Differentiated Thyroid Cancer (DTC) is distinguished for having a low mortality but it could reach recurrence until $30 \%$ in five years. The prediction of the risk of recurrence in Chile is different from ATA. The use of the stimulated thyroglobulin (Tg) post-surgery in the prediction of the risk is controversial. We present a cohort applying a new local protocol that includes the Tg for supporting the discrimination of the patients for offer low doses or radio iodine.

OBJECTIVE: Asses if the local risk classification (LC) that we use allows us to discriminate the response to the treatment (RT).

METHODS: Analysis of medical records from the patients with total thyroidectomy for DTC during 2013. Compared the LC with de ATA risk stratification scale. We evaluated the response to the treatment after a year of evolution according with the levels of suppressed and stimulated Tg and images. The results were divided in excellent or acceptable/incomplete.

For the statistical analysis we used Mann-Whitney proof, for the continuous variables and X2 for non-continuous variables. We excluded patients with positive Tg Antibodies.

Tab 1. Local Risk Classification

\begin{tabular}{|c|c|}
\hline Risk HSJDD & Characteristics \\
\hline Very low Risk & $\begin{array}{l}\text { Tumor less or equal of } 2 \mathrm{~cm} \text { uni or multifocal: } \\
\text { - Etapification ultrasound scan and cervical exploration without lymph nodes } \\
\text { - Vascular invasion (-) } \\
\text { - Without aggressive histology. } \\
\text { - Minimal extrathyroid extension (Adipose tissue) } \\
\text { - Regional lymph node metastasis in definitive biopsy < or }=5 \mathrm{~mm} \text { and } \\
\text { less of } 5 \text { lymph nodes. Tg post surgery }<2 \mathrm{ng} / \mathrm{dl} \text {. }\end{array}$ \\
\hline Low Risk & $\begin{array}{l}\text { Tumor less or equal of } 4 \mathrm{~cm} \text { uni o multifocal: } \\
\text { - Aggressive Histology } \\
\text { - vascular invasion(+). } \\
\text { - Minimal extrathyroid extension ( muscle) } \\
\text { - Lymph nodes in definitive biopsy }>5 \mathrm{~mm} \text { and } / \text { or } \geq 5 \text { lymph node } \\
\text { metastasis. } \text { Tg } 2-20 \mathrm{ng} / \mathrm{dl} \text {. }\end{array}$ \\
\hline Intermediate Risk & $\begin{array}{l}\text { Tumor less or equal of } 2 \mathrm{~cm} \text { : } \\
-\mathrm{Tg} 20-50 \mathrm{ng} / \mathrm{dl} \\
\text { Tumor between } 2 \text { y } 4 \mathrm{~cm} \text { : } \\
\text { - Aggressive Histology. } \\
\text { - Vascular invasion (+). } \\
\text { - } \quad \text { Lymph nodes metastasis in definitive biopsy }>5 \mathrm{~mm} \text { and } / \text { or } \geq 5 \text { lymph } \\
\text { nodes metastasis. } \\
\text { - Complete resection of macroscopic extrathyroid extension. } \mathrm{Tg} 20-50 \\
\mathrm{ng} / \mathrm{dl} \text {. }\end{array}$ \\
\hline $\begin{array}{l}\text { High Risk } \\
150 \mathrm{mCi} \mathrm{RI}\end{array}$ & $\begin{array}{l}\text { - Any } \mathrm{T} \text { with } \mathrm{Tg} \text { more than } 50 \mathrm{ng} / \mathrm{dl} \text {. } \\
\text { - Extrathyroid extension no resected or any } \mathrm{T} \text { with distant metastasis. }\end{array}$ \\
\hline
\end{tabular}

RESULTS: 96 patients were analysed from them $87,5 \%$ were women. The mean age was 50,4 years $\pm 14,5$. The thyroidectomy was total in a $100 \%$. Histological type was: 92,7\% papillary, 3,1\% follicular, 4,2 \% mixed. 68,7\% received radio iodine in doses from 30 to $150 \mathrm{mCi}$; in the group of very low risk LC no one went to ablation tab 2.

\begin{tabular}{|c|c|c|c|}
\hline \multirow{2}{*}{$\begin{array}{l}\text { Local Risk } \\
\text { Clasiffication }\end{array}$} & \multicolumn{3}{|c|}{ Dose of Radio lodine } \\
\hline & Median & P25 & P75 \\
\hline Very Low Risk & 0 & 0 & 0 \\
\hline Low Risk & 30 & 30 & 100 \\
\hline Intermediate Risk & 100 & 100 & 150 \\
\hline High Risk & 150 & 150 & 150 \\
\hline
\end{tabular}

RT was excellent in $74 \%$, acceptable in $20 \%$ and incomplete in $6,2 \%$. Using the cohort value of the Tg lower than $2 \mathrm{ng} / \mathrm{dl}$, we get un LR of 0,22 for predicting a good response.

Comparing the RT between two scales (ATA vs LC): In the Very Low risk the response was excellent in $100 \%(p=$ $<0,001)$. For the rest groups see fig 1 .

Fig 1. Comparing the RT between two scales

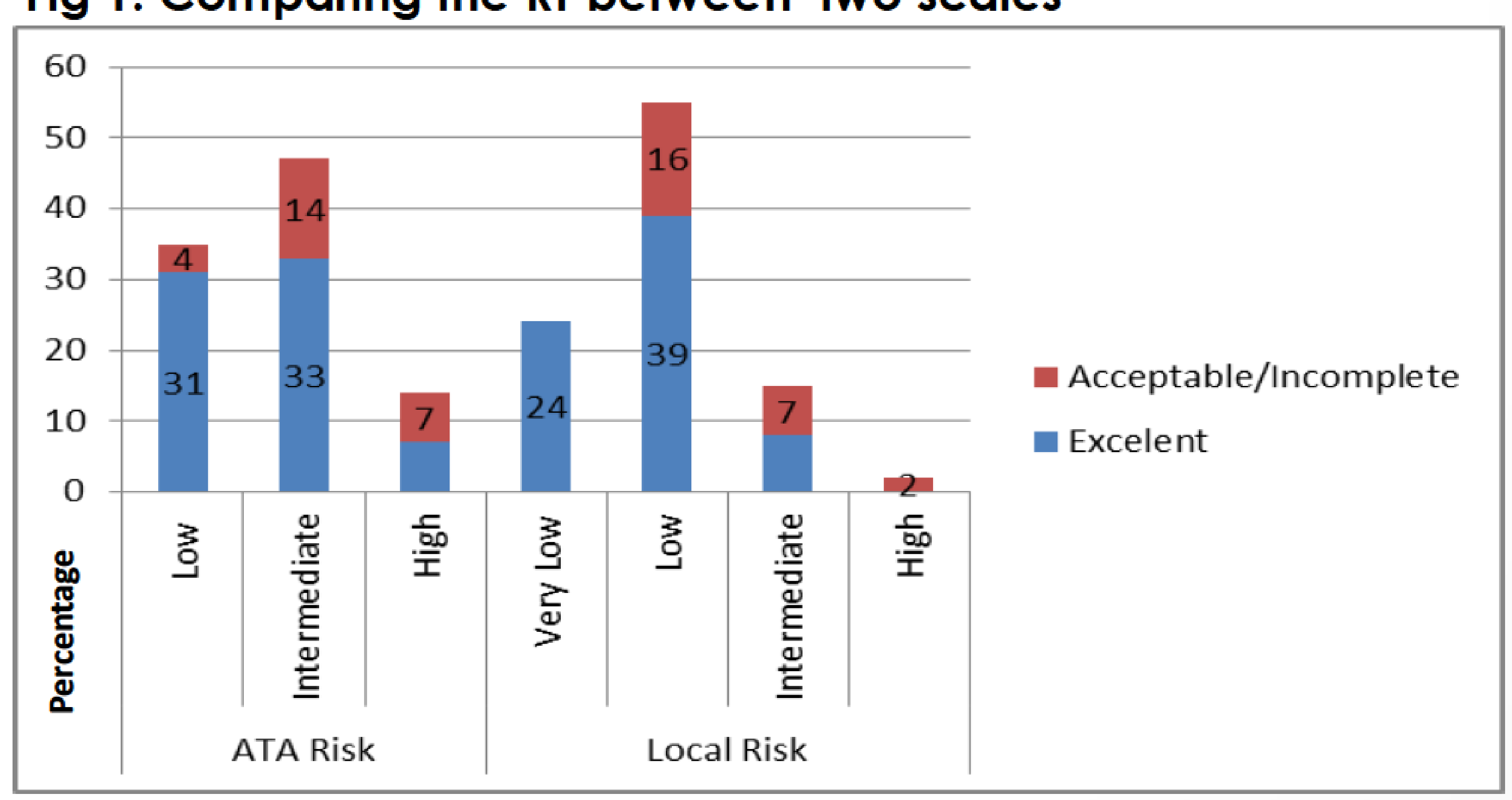

Low Risk ATA vs LC. $p=0,0$

Intermediate Risk ATA vs LC. $p=0,229$

High Risk ATA vs LC. $p=0,47$.

CONCLUTIONS: In the local classification all the patients with very low risk presented excellent response to the treatment, allowing discriminate better this group. The rest categories concentrated patients with a worse evolution.

References:

. Prognostic factors in differentiated thyroid carcinomas and their implications for current staging classifications. A. Jukkola, et al. Endocrine-Related Cancer 2004.

2. Impact of Degree of Extrathyroidal Extension of Disease on Papillary Thyroid Cancer Outcome. J. S. Radowsky, et al. Thyroid 2014.

3. Ablation with Low-Dose Radioiodine and Thyrotropin Alfa in Thyroid Cancer. Ujjal Mallick, et al. N Engl J Med 2012.

4. Revised American Thyroid Association Management Guidelines for Patients with Thyroid Nodules and Differentiated Thyroid Cancer. D. S. Cooper, et al. Thyroid 2009. 